See Article page 456 .

\section{Commentary: Surgery for ground-glass nodules: Free lunch or slippery slope?}

\author{
Nasser Altorki, MD, and Marc Vimolratana, MD
}

The widespread use of computed tomography of the chest in routine clinical practice and the implementation of computed tomography scanning for lung cancer screening has dramatically increased the detection of ground-glass or subsolid (SSN) pulmonary nodules. In most instances, persistent SSN less than $5 \mathrm{~mm}$ in size represent focal proliferative lesions known as atypical alveolar hyperplasia that are considered the earliest progenitor lesions of invasive adenocarcinoma of the lung. Larger SSNs typically harbor adenocarcinoma in situ, minimally invasive adenocarcinoma, and less commonly frankly invasive adenocarcinoma. The precise biological behavior of these lesions is unclear, as many remain unchanged in size and appearance for many years. However, approximately $20 \%$ to $40 \%$ of these nodules either grow or develop a solid component suggestive of a more invasive malignancy. ${ }^{1}$ This uncertainty in clinical behavior commits patients to either frequent, repeat imaging or even occasionally to surgical resection. When surgical resection is contemplated, the extent of parenchymal resection is an important consideration, given the indolent nature of these nodules.

In this issue of the Journal, Zhang and colleagues ${ }^{2}$ from Fudan University present what to our knowledge is the largest series comparing lobar with sublobar resection in patients presenting with adenocarcinoma in situ and minimally invasive adenocarcinoma. Impressively, $97 \%$ of patients had their resection performed using minimally

\footnotetext{
From the Division of Thoracic Surgery, Weill-Cornell Medicine, New York-Presbyterian Hospital, New York, NY.

Dr Vimolratana reported no conflicts of interest. Dr Altorki receives clinical trial support from Astra Zeneca LLC and research support from NCI Moonshot (UG3CA244697).

The Journal policy requires editors and reviewers to disclose conflicts of interest and to decline handling or reviewing manuscripts for which they may have a conflict of interest. The editors and reviewers of this article have no conflicts of interest.

Received for publication Dec 15, 2020; revisions received Dec 15, 2020; accepted for publication Dec 16, 2020; available ahead of print Dec 25, 2020.

Address for reprints: Nasser Altorki, MD, Division of Thoracic Surgery, WeillCornell Medicine, New York-Presbyterian Hospital, 1300 York Ave, New York,

NY 10065 (E-mail: nkaltork@med.cornell.edu).

J Thorac Cardiovasc Surg 2022;163:465-6

$0022-5223 / \$ 36.00$

Copyright (c) 2021 by The American Association for Thoracic Surgery

https://doi.org/10.1016/j.jtcvs.2020.12.073
}

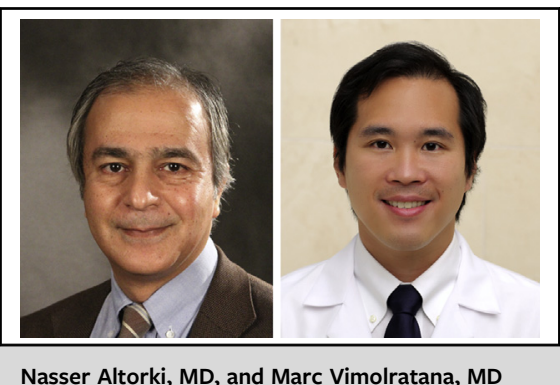

Nasser Altorki, MD, and Marc Vimolratana, MD

$$
\begin{aligned}
& \text { CENTRAL MESSAGE } \\
& \text { Wedge resection for small GGOs } \\
& \text { harboring AIS or MIA is associ- } \\
& \text { ated with equivalent survival and } \\
& \text { fewer complications when } \\
& \text { compared with those after seg- } \\
& \text { mentectomy and lobectomy. }
\end{aligned}
$$

invasive techniques despite the fact that the median nodule size was only $9 \mathrm{~mm}$. Complications occurred in $2 \%$ of patients, and there were no 30-day deaths among 1644 patients. Five-year recurrence-free and overall survival were $100 \%$ and $98.8 \%$, respectively, regardless of the extent of parenchymal resection.

The message is loud and clear; do not do a lobectomy when a sublobar resection (preferably wedge) should suffice. We congratulate the authors on their impressive perioperative results and agree with their principal message. However, it is far from certain that surgical resection is or should be the principal recommendation for patients with SSN, particularly those $<1 \mathrm{~cm}$ in size. The risk of radiation-induced cancers as a result of frequent repeat imaging cited by the authors as one rationale for resection is based on hypothetical mathematical modelings based on radiation doses extrapolated from atomic bombings. In fact, the American Association of Physicists in Medicine (AAPM) states that "predictions of hypothetical cancer incidence and mortality from the use of diagnostic imaging are highly speculative. The AAPM, and other radiation protection organizations, specifically discourages these predictions of hypothetical harm." 3 Given the large number of patients with SSN seen by the Fudan group, we believe that the authors are uniquely positioned to answer the seminal question about SSN: active surveillance or resection?

A randomized trial allocating patient to immediate versus delayed resection based on predefined criteria will not only provide guidance about the optimal 
strategy but more precisely define the triggers for surgical intervention. Without data from controlled clinical trials, surgical resection with the intention of intercepting cancer progression rather than being a "free lunch" may be a slippery slope toward unnecessary and potentially harmful interventions that betray our "do no harm" axiom.

\section{References}

1. Kobayashi Y, Mitsudomi T. Management of ground-glass opacities: should all pulmonary lesions with ground-glass opacity be surgically resected? Transl Lung Cancer Res. 2013;2:354-63.

2. Zhang Y, Ma X, Shen X, Wang S, Li Y, Hu H, et al. Surgery for pre- and minimally invasive lung adenocarcinoma. J Thorac Cardiovasc Surg. 2022;163:456-64.

3. American Association of Physicists in Medicine. AAPM position statement on radiation risks from medical imaging procedures. Available at: https://www.aapm. org/org/policies/details.asp?type =PP\&id=439. Accessed 2018.
See Article page 456.

\section{Commentary: Computed tomography screening for lung cancer at large in China: Early cure or definitive overtreatment?}

\author{
Nirmal K. Veeramachaneni, MD
}

In this issue of the Journal, Zhang and colleagues ${ }^{1}$ report the results of surgical resection of incidentally found pure ground-glass opacities (GGO; 76.3\%) or part solid-GGO $(22.6 \%)$. In this single-center study of predominantly female, middle-aged, never-smokers, patients underwent computed tomography (CT) scans for arbitrary reasons. Almost none of these patients would qualify for lung cancer screening based on current guidelines. ${ }^{2} \mathrm{CT}$ imaging was completed as part of a regular health examination due in part to the low cost and wide availability of CT scans. Now faced with a lesion found on a CT scan, these patients uniformly underwent surgery. Patients in this study did remarkably well with wedge resection. None had nodal spread of disease, and 5-year recurrence-free survival was $100 \%$. Even in those patients found to have invasive cancer on final pathological evaluation, lack of a lobectomy did not

\footnotetext{
From the Department of Cardiovascular and Thoracic Surgery, University of Kansas Health System, Kansas City, Kan.

Disclosures: The author reported no conflicts of interest.

The Journal policy requires editors and reviewers to disclose conflicts of interest and to decline handling or reviewing manuscripts for which they may have a conflict of interest. The editors and reviewers of this article have no conflicts of interest.

Received for publication Dec 31, 2020; revisions received Dec 31, 2020; accepted for publication Jan 4, 2021; available ahead of print Jan 13, 2021.

Address for reprints: Nirmal K. Veeramachaneni, MD, Department of Cardiovascular and Thoracic Surgery, University of Kansas Health System, 4000 Cambridge St, Kansas City, KS 66160 (E-mail: nveeramachaneni@kumc.edu).

J Thorac Cardiovasc Surg 2022;163:466-7

$0022-5223 / \$ 36.00$

Copyright (c) 2021 by The American Association for Thoracic Surgery

https://doi.org/10.1016/j.jtcvs.2021.01.008
}

Check for updates

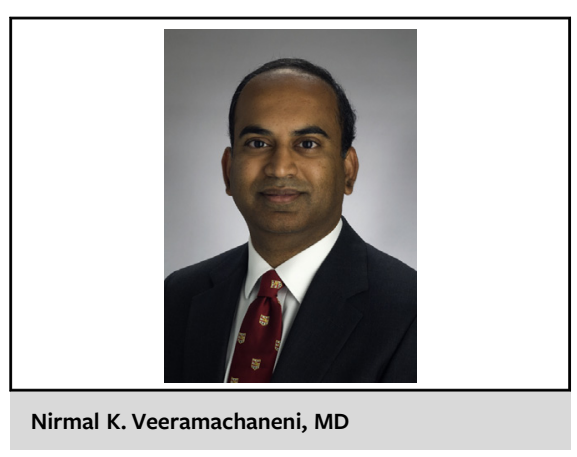

CENTRAL MESSAGE

Lung cancer screening without consideration for pretest probability leads to surgeries of unclear benefit.

worsen the recurrence rate. Are the authors documenting a strategy of curing lung cancer early, or is this an exercise in overtreatment?

Previously reported results from JCOG0201 show significantly different 5 -year overall survival between patients with any GGO and those with "pure solid" lesions. ${ }^{3}$ With the presence of GGO, survival was $>90 \%$, regardless of solid (invasive cancer) component size. ${ }^{3}$ In the study cohort of Zhang and colleagues ( $98.9 \%$ with GGO), efforts to classify tumor invasion on frozen sections might have been unnecessary, given the positive prognostic advantages associated with GGO. As shown in JCOG0201, and substantiated in the current article, nodal spread is rare in these cases, and aggressive surgery is not required. ${ }^{3}$

The authors note that one motivation to pursue surgery is to avoid unnecessary CT scans. This poses a conundrum, as these patients still required CT scans for long-term followup even when surgical resection was completed. Although 